\title{
The relationship of soil loss by interrill erosion to slope gradient
}

\author{
Dennis M. Fox ${ }^{\mathrm{a}, *}$, Rorke B. Bryan ${ }^{\mathrm{b}}$ \\ a UMR 5651 “ESPACE”' du CNRS, Université de Nice, 98 Blvd. Edouard Herriot, B.P. 209-06204, Nice \\ Cedex 3, France \\ ${ }^{\mathrm{b}}$ Soil Erosion Laboratory, Division of Physical Sciences, Scarborough Campus, University of Toronto, 1265 \\ Military Trail, Scarborough, ON, Canada MIC 1A4
}

Received 7 March 1997; received in revised form 17 March 1998; accepted 17 June 1999

\begin{abstract}
The influence of slope gradient on erosion rate differs for rill and interrill conditions. Rill erosion increases substantially more with increasing slope gradient than interrill erosion. Combining the two erosion processes into single data sets led to the development of regression equations (e.g., USLE) that overestimated the effect of slope gradient on erosion rate for low slope gradients and short slopes. This study investigated the change in interrill erosion rate with slope gradient and examined its relationship to runoff velocity. A sandy loam (grey brown luvisol) was packed in $100 \times 40 \times 10 \mathrm{~cm}^{3}$ soil trays and subjected to simulated rainfall for a period of $75 \mathrm{~min}$. Rain-impacted flow erosion and downslope splash were monitored, and runoff velocity measurements were made at three positions within the flume. Downslope splash erosion never accounted for more than $20 \%$ of the total erosion. Rain-impacted flow erosion peaked early in the simulation then decreased to a constant rate; erosion rate was therefore probably detachment-limited. For a constant runoff rate, rain-impacted flow erosion increased roughly with the square root of slope gradient, as did the runoff velocity. Soil loss was correlated $(0.81)$ with runoff velocity under the experimental conditions. (C) 1999 Elsevier Science B.V. All rights reserved.
\end{abstract}

Keywords: Soil loss; Interrill erosion; Slope gradient

\section{Introduction}

Despite recent advances in erosion prediction using physically based models, empirical relationships based on the Universal Soil Loss Equation (USLE) remain the most

\footnotetext{
* Corresponding author
} 
practised method of estimating erosion hazards. In the early version of the USLE, soil erosion was predicted as a power function of slope gradient. Slope exponents for data grouping both interrill and rill erosion ranged from about 1 to 2 . When data for short slopes or slopes of low inclination were extracted and analyzed separately, the soil loss/slope gradient relationship was approximately linear or less than linear (power exponent of about 0.8) (McCool et al., 1987). Several studies (Lattanzi et al., 1974; Watson and Laflen, 1986; McIsaac et al., 1987; Meyer and Harmon, 1989; Huang and Bradford, 1993) have confirmed that the power relationship of the USLE overpredicts interrill erosion rate by as much as two to three times (Torri, 1996), and the relationship is better described as linear or less than linear. These modifications have been taken into account in the Revised USLE which uses distinct slope relationships for different conditions (Renard et al., 1994).

Although considerable progress in establishing a more accurate relationship between slope gradient and interrill erosion rate has been made, the physical basis for this relationship remains largely unaccounted for. One hypothesis for the taper in erosion rate at greater slope gradients is that the impact gradient of falling drops is much greater and, hence, less effective in detaching particles (Singer and Blackard, 1982). However, this is contradicted by the theoretical and empirical results of Torri and Poesen (1992), who conclude that surface slope has a positive effect on splash detachment. Another possibility is that the taper reflects a transition in the erosion regime from transportlimited to detachment-limited (Meyer and Harmon, 1989), though this could not be affirmed quantitatively. The transport capacity threshold depends on several interacting factors such as runoff depth and velocity, sediment concentration, settling velocity of particles in entrainment, and the efficiency of entrainment (Rose et al., 1983; Gerits et al., 1990), so routine measurements of runoff discharge and sediment concentration are not sufficient for identifying the transport capacity threshold easily.

In studies independent of slope gradient, interrill erosion has been shown to be directly related to runoff velocity (Moss, 1988; Kinnell, 1990). Raindrops striking shallow runoff produce clouds of particles in the flow. Particles with settling velocities lower than the runoff velocity settle to the surface downstream of the initial impact zone; the downstream travel distance of these particles is determined by the flow velocity, the particle fall velocity in water, and the height to which the particles are lifted (Kinnell, 1990). As the Reynolds number of unimpacted flow increases and the flow passes from laminar to turbulent, raindrop impacts create disturbances which are sufficiently long-lasting for the entire flow to be affected by drop-imposed turbulence and not just isolated impact sites (Moss, 1988). The description of the process accounts for observations of the ability of shallow rain-impacted flows to erode soil materials more rapidly than unimpacted flows of similar depth and velocity (Moss et al., 1978; Walker et al., 1978; Guy et al., 1987). Under conditions of turbulent flow, and for a given soil and rainfall intensity, erosion rate would be expected to vary directly with runoff velocity (Moss, 1988; Kinnell, 1990).

Several studies have examined the influence of shear velocity or unit stream power on transport capacity for rilling conditions (Govers and Rauws, 1986; Govers, 1990). For rill erosion, no apparent influence of slope gradient on runoff velocity within a rill was observed, though the Manning equation predicts a slope coefficient of about 0.3 
(Govers, 1992). However, the relationship between runoff velocity and slope gradient, and the implications of this on soil loss, have yet to be considered for interrill conditions.

The objectives of this experiment are therefore: (1) to investigate the relationship between runoff velocity and slope gradient for interrill conditions, and (2) to see if variations in runoff velocity can account for the relationship observed between interrill soil loss and slope gradient.

\section{Materials and methods}

\subsection{Experimental set-up}

The soil used in the study is the Pontypool Sandy loam (50\% sand, $22 \%$ silt, and $28 \%$ clay), a grey brown Luvisol from Southern Ontario, Canada. It was collected from the top $20 \mathrm{~cm}$ in the A horizon of a well-drained site, and the dominant minerals in the clay fraction were vermiculite and fine-grained mica (Kodama et al., 1993). It was air-dried to a moisture content of about $8 \%$ and passed through a $4.0 \mathrm{~mm}$ sieve. For each rainfall simulation, soil was packed in $2.0 \mathrm{~cm}$ layers in a $100 \times 40 \times 10 \mathrm{~cm}^{3}$ soil tray to a mean bulk density of $1.29 \mathrm{~g} \mathrm{~cm}^{-3}$ (st. dev. $=0.03 \mathrm{~g} \mathrm{~cm}^{-3}$ ). Each layer was lightly compacted with a board and the surface roughened by hand before adding the next layer (Kinnell and Cummings, 1993). The tray was then set at one of five slope gradients $(2.5 \%$, $11.5 \%, 20.5 \%, 30 \%, 40 \%)$ and subjected to simulated rainfall. Rainfall simulations were conducted with a sprinkler type system similar to Poesen et al. (1990), and rainfall characteristics were reported to be similar to natural rainfall, though the intensity varied slightly between replicates. Mean rainfall intensity was $49.1 \mathrm{~mm} \mathrm{~h}^{-1}$ with a range of $38.2 \mathrm{~mm} \mathrm{~h}^{-1}$ to $56.3 \mathrm{~mm} \mathrm{~h}^{-1}$ and a standard deviation of $4.7 \mathrm{~mm} \mathrm{~h}^{-1}$. For most replicates, rainfall intensity was slightly greater in the lower portion of the tray. Tap water was used for rainfall simulations, and although lower erosion rates have been observed for some soils when using tap water instead of deionized water (Shainberg et al., 1992), it was assumed the effects were negligible for this soil which is relatively insensitive to chemical dispersion due to its clay mineralogy and low sodium content. Comparisons with deionized water were not made, however, and erosion rates reported here may be lower if distilled water were used. The sequence of slope gradients was assigned randomly, and there was no systematic variation in intensity with slope. For each slope gradient, 10 replicates were included.

\subsection{Soil loss measurements}

Runoff was sampled every 2 min to 3 min during the first 15 min of the simulation and then every $5 \mathrm{~min}$ for a total duration of $75 \mathrm{~min}$. Sediments splashed off the front of the tray were collected on splash boards, so only net downslope splash erosion was measured and not total splash erosion, for which sediments are splashed in all directions. Lateral downslope splash from near the tray edges would have been lost, so downslope splash erosion rates are slightly underestimated. Splash and runoff samples were 
oven-dried at $105^{\circ} \mathrm{C}$ to obtain soil loss expressed in $\mathrm{g} \mathrm{m}^{-2} \mathrm{~min}^{-1}$. Water splashed off the side of the tray was also collected and used in calculating infiltration rate. The infiltration results are presented in a separate publication (Fox et al., 1997).

\subsection{Runoff velocity measurements}

In addition to sampling runoff, measurements of surface flow velocity were made at three locations within the tray during a 15-min period between $75 \mathrm{~min}$ and $90 \mathrm{~min}$ after the start of the simulation. Velocity was measured over a distance of $20 \mathrm{~cm}$ in ranges of $10-30 \mathrm{~cm}, 30-50 \mathrm{~cm}$, and $50-70 \mathrm{~cm}$ from the trough, respectively. Measurements were made using the dye method (Luk and Merz, 1992), and for each location and tray about 5-10 repeated values were observed. Mean flow velocity was calculated from maximum velocity using a conversion factor of 0.36 (Luk and Merz, 1992).

\section{Results}

\subsection{Interrill erosion rates}

Before presenting the mean final soil loss rates as a function of slope gradient, representative replicates for each slope gradient will be considered to highlight trends within a rainfall simulation. These trends are shown in Fig. 1 where all slope gradients tend to show a peak in sediment load early in the simulation followed by a decrease to a final constant rate. The magnitude of the peak increases with increasing slope gradient.

Mean final soil loss rates for each slope gradient are shown in Fig. 2. Rain-impacted flow erosion is the dominant form of erosion and downslope splash erosion never accounts for more than $20 \%$ of total interrill erosion. The increase in splash erosion with slope is consistent with the model of Torri and Poesen (1992), and the erosion values are similar to those of Lattanzi et al. (1974) and Moss (1988), though splash accounts for a higher proportion of the total erosion in this case than it did for Moss (1988). Truman and Bradford (1995) found that splash erosion was greater than rain-impacted flow erosion in their experiments, but they measured splash erosion in all directions, used smaller erosion surfaces $\left(0.14 \mathrm{~m}^{2}\right.$ and $\left.0.32 \mathrm{~m}^{2}\right)$ and greater rainfall intensities $(50 \mathrm{~mm}$ $\mathrm{h}^{-1}$ to $100 \mathrm{~mm} \mathrm{~h}^{-1}$ ), conditions which favour the relative importance of splash erosion.

The relationship between soil loss or rain-impacted flow erosion and slope gradient appears approximately linear as in the studies cited above. In an analysis of covariance $\left(r^{2}=0.86\right)$, both net downslope erosion and rain-impacted flow erosion were significantly related to slope gradient and rainfall intensity $(\alpha=0.001)$. However, the distinct influence of slope gradient on detachment rate is confounded by variations in runoff rate. In addition to influencing the raindrop impact gradient, runoff velocity and effective rainfall intensity, slope gradient has been shown to influence infiltration rate (Poesen, 1984; Fox et al., 1997). In this experiment, infiltration rate decreased from about $9.8 \mathrm{~mm} \mathrm{~h}^{-1}$ to $7.5 \mathrm{~mm} \mathrm{~h}^{-1}$ with increasing slope gradient. The principal factor affecting runoff rate within any slope gradient was the variation in rainfall intensity 

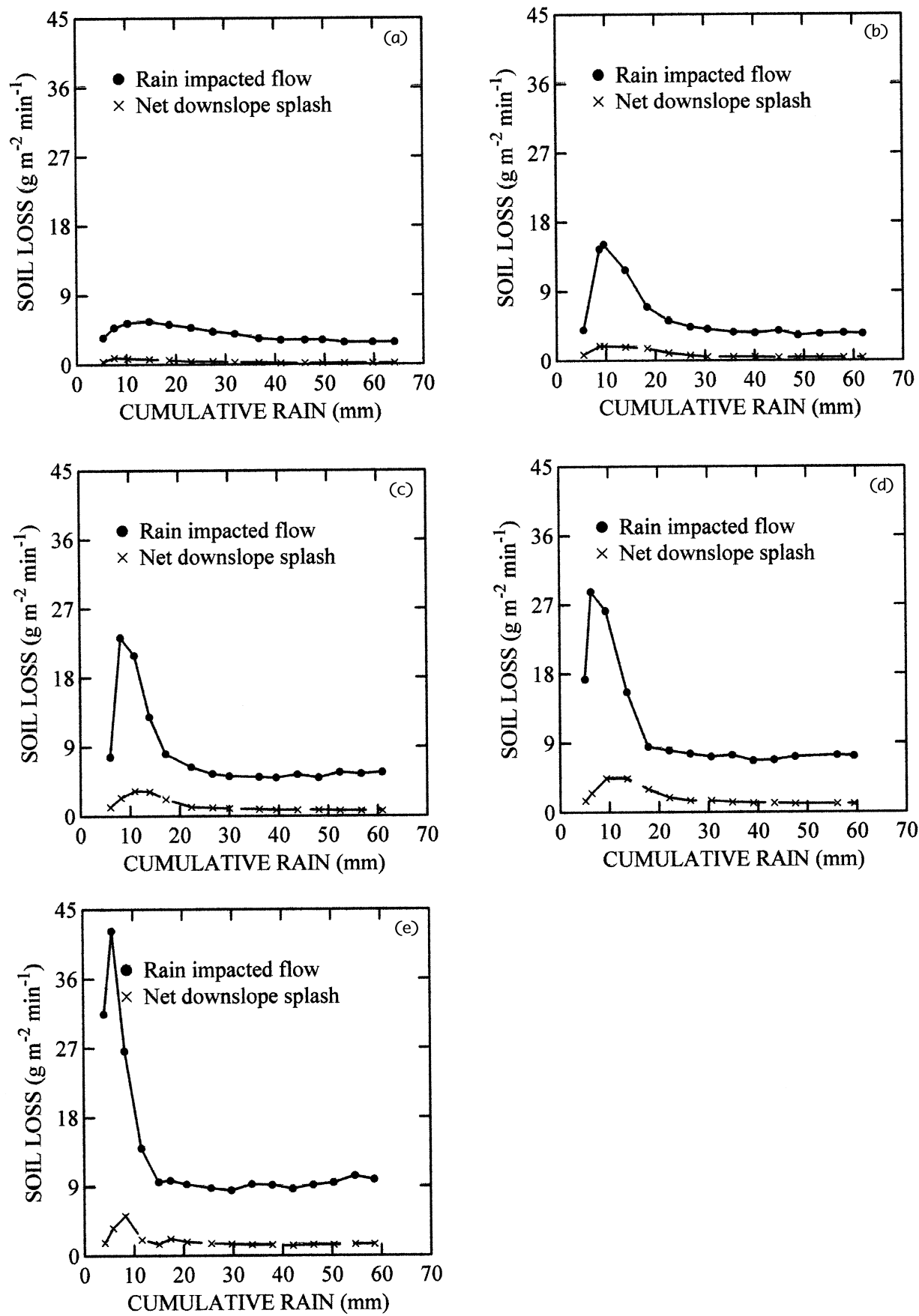

Fig. 1. Trends in erosion rate during the rainfall simulation for representative replicates for each slope gradient: (a) $2.5 \%$, (b) $11.5 \%$, (c) $20.5 \%$, (d) $30 \%$, (e) $40 \%$. 


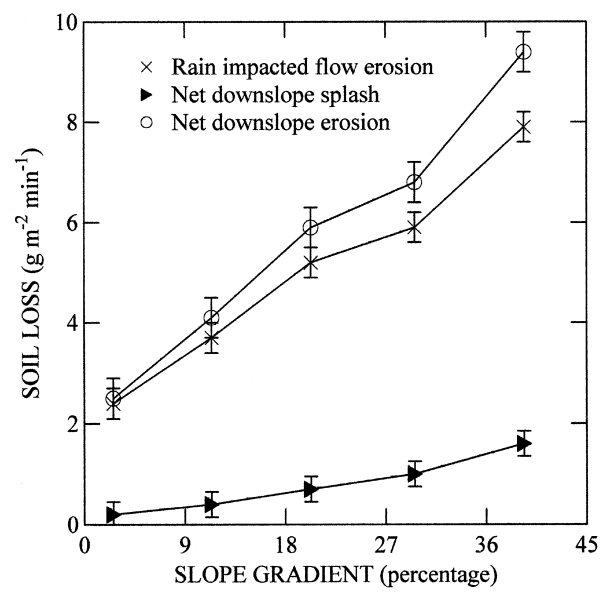

Fig. 2. Mean equilibrium soil loss rates (error bars are \pm 1 standard error).

referred to earlier. Non-linear regression equations can be used to distinguish the slope from the discharge effect.

Some authors (Carson and Kirkby, 1972; Band, 1985; Mathier et al., 1989; Huang and Bradford, 1993; Mathier and Roy, 1996) have used power regression equations to relate soil loss to runoff (or rainfall intensity) and slope gradient. The following equation was used in this study to distinguish the slope effect from that of runoff rate. Rain-impacted flow erosion rate alone was used because it can be physically related to discharge and flow velocity. Coefficients for runoff rate and slope gradient are shown in Table 1. The coefficients are consistent with those of other experiments: Band (1985) had $m$ and $n$ coefficients of 2.02 and 0.84, respectively, and Mathier et al. (1989) had values of 1.5 and 0.9 , respectively. Slope length was much shorter in this experiment than in the studies of Band (1985) and Mathier et al. (1989) and this may explain the lower slope coefficient observed here. For a constant runoff rate, interrill erosion increases roughly with the square root of slope gradient.

$$
Q_{\mathrm{s}}=k Q_{\mathrm{w}}^{m}(\tan \alpha)^{n}
$$

where $Q_{\mathrm{s}}=$ erosion rate $\left(\mathrm{g} \mathrm{m}^{-2} \mathrm{~min}^{-1}\right), Q_{\mathrm{w}}=$ runoff rate $\left(\mathrm{cm}^{3} \mathrm{~s}^{-1}\right), k, m, n=$ regression coefficients, $\tan \alpha=$ tangent of slope.

Table 1

Coefficients for regressions on soil loss and runoff velocity using Eqs. (1) and (2) (values in parenthesis are lower and upper $95 \%$ confidence limits, respectively)

\begin{tabular}{lllll}
\hline Dependent variable & $k$ & $m$ & $n$ & $r^{2}$ \\
\hline$(1)$ Soil loss $\left(Q_{\mathrm{s}}\right)$ & $0.30(-0.01-0.62)$ & $2.37(1.70-3.03)$ & $0.43(0.33-0.62)$ & 0.79 \\
$(2)$ Flow velocity $\left(V_{\text {av }}\right)$ & $0.27(0.004-0.55)$ & $1.89(1.25-2.52)$ & $0.45(0.35-0.55)$ & 0.87 \\
\hline
\end{tabular}




\subsection{Runoff velocity}

Mean flow velocities are presented in Fig. 3 and an analysis of variance $\left(r^{2}=0.92\right)$ confirms that the relationship between flow velocity and both slope gradient and position within the flume is significant $(\alpha=0.001)$. The downslope section is the one closest to the tray outlet. The greatest increase in velocity with slope gradient occurs between $2.5 \%$ and $11.5 \%$, with lesser increases thereafter. The large increase between $30 \%$ and $40 \%$ may result from lower resistance to flow in micro-channels formed in the $40 \%$ slope.

Fig. 3 also shows that the increase in flow velocity with slope section within slope gradient is constant for slopes equal to or less than $11.5 \%$. For slopes equal to or greater than $20 \%$, there is a larger increase between the midslope and downslope positions than between the midslope and upslope ones. Runoff velocity may approach a constant rate over a shorter distance on steeper slopes. Eq. (1) was modified to:

$$
V_{\mathrm{av}}=k Q_{\mathrm{w}}^{m}(\tan \alpha)^{n}
$$

where $V_{\mathrm{av}}=$ mean runoff velocity $\left(\mathrm{cm} \mathrm{s}^{-1}\right)$, and used to identify changes in velocity with slope gradient independently of discharge. The mean velocity of the three positions within the soil tray was used, and the coefficients for runoff rate and slope gradient are presented in Table 1. Both regression coefficients deviate from expected theoretical values. The value of $n(0.45)$ is greater than the values used for slope in the Manning equation (0.3). Within the $1-\mathrm{m}$ soil tray, runoff velocity had not reached a steady rate and the increase in velocity between positions was greater on steeper slopes, so this may account for the greater $n$ value found here. The Manning equation was developed for channel flow, and in the interrill conditions studied here, micro-channels developed only on steeper slopes. Furthermore, in interrill conditions, the contribution of water moved downslope by splash is probably not negligible, and this is, of course, not taken into account by the Manning equation.

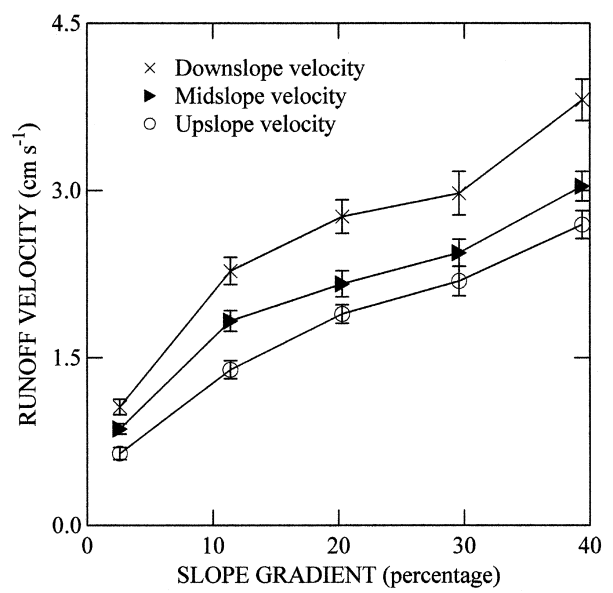

Fig. 3. Mean runoff velocities for each slope section (error bars are \pm 1 standard error). 
The value of $m$ (1.89) is also greater than expected. For values greater than 1, runoff velocity increases so rapidly with discharge that flow depth decreases with increasing runoff. If $Q=v h w$, where $v=$ runoff velocity, $h=$ runoff depth, and $w=$ runoff width, and if $w$ is considered equal to 1 , then $Q=h^{-1.12}$ for a value of $m$ equal to 1.89 . The velocity results represent the means of about 700 measurements $(50$ trays $\times 3$ positions per tray $\times$ four to six values per position) using a standard method, so it is unlikely that the trend is the result of experimental error. In addition, the trend is consistent for all of the slope angles. Interrill runoff differs from rill runoff (or channel flow) in three important ways: the first is that effective " width" does not correspond to soil tray width since flow concentrates more or less in large shallow flows or in narrow micro-channels according to slope angle, surface roughness, and discharge. The second is that "depth", varies considerably since roughness elements are frequently as great or greater than runoff depth as the interrill runoff "meanders" around soil clods. The third is that resistance to flow in interrill conditions differs greatly from channel flow because of the relative height of surface roughness to flow depth as described above.

\subsection{The relationship between soil loss and runoff velocity}

It is obvious from the nearly identical values for $n$ in Table 1 that predicted values of rain-impacted flow erosion and runoff velocity for a constant runoff rate (using Eqs. (1) and (2)) are highly correlated $\left(r^{2}=0.99\right)$, confirming the close relationship between runoff velocity and rain-impacted flow erosion. In addition, linear regressions were performed on the uncorrected rain-impacted flow erosion rates against runoff velocity and some hydraulic parameters. These were developed for river channel flow but are commonly applied to rill erosion (Govers, 1990). The theoretical suitability of these parameters for interrill erosion is questionable due to the relative height of roughness elements compared to runoff depth, as discussed above, but the parameters include characteristics (runoff velocity and depth, slope gradient) important for erosion in general. The parameters tested were mean runoff velocity $(u)$, shear stress $(\rho g R S)$, shear velocity $\left((g R S)^{0.5}\right)$, and unit stream power $(u S)$, where $\rho$ is fluid density, $g$ is acceleration due to gravity, $r$ is hydraulic radius (considered equal to depth), and $S$ is slope (tan) (Govers, 1990).

Regression results are summarised in Table 2 for both soil loss rate $\left(\mathrm{g} \mathrm{m}^{-2} \mathrm{~min}^{-1}\right)$ and sediment concentration $\left(\mathrm{g}^{-1}\right)$. The best overall parameter was the mean runoff

Table 2

Linear regression results for different hydraulic variables

\begin{tabular}{|c|c|c|c|c|}
\hline \multirow[t]{2}{*}{ Independent variable } & \multicolumn{2}{|c|}{ Erosion rate $\left(\mathrm{g} \mathrm{m}^{-2} \min ^{-1}\right)$} & \multicolumn{2}{|l|}{ Sediment load $\left(\mathrm{g} \mathrm{l}^{-1}\right)$} \\
\hline & Regression equation & $r^{2}$ & Regression equation & $r^{2}$ \\
\hline Mean velocity & $y=2.17 x+0.24$ & 0.80 & $y=3.35 x+0.97$ & 0.82 \\
\hline Shear velocity & $y=1.47 x+0.42$ & 0.23 & $y=2.57 x+0.33$ & 0.32 \\
\hline Shear stress & $y=0.24 x+2.45$ & 0.23 & $y=0.42 x+3.92$ & 0.32 \\
\hline Unit stream power & $y=4.45 x+2.54$ & 0.76 & $y=7.11 x+4.40$ & 0.83 \\
\hline
\end{tabular}


velocity. The intercept coefficient for runoff velocity was not significantly different from 0 for both erosion rate and sediment concentration. Adding a slope component to runoff velocity (unit stream power) did not increase the explained variance.

\section{Discussion}

The soil erosion pattern shown in Fig. 2, where erosion peaks early in the rainfall simulation and then decreases to a final constant rate may be accounted for by changes in surface soil cohesion. The peak corresponds to the period when aggregates are being sheared under raindrop impact and the soil shear strength decreases as the soil nears saturation. Slaking may also be an important disaggregating force in the early part of the simulation. As runoff increases in the first few minutes, loose sediments on the surface are flushed off. The initial peak in concentration tends to increase with increasing slope gradient. This reflects greater detachment and transport capacities at greater slope gradients. Continued raindrop impact increases the near-surface bulk density and resistance to detachment, so the erosion rate drops to an equilibrium level marking the balance between the erosive forces of splash and rain-impacted flow detachment and the resistance of the soil surface. The final soil loss rate is lower than the initial peak rate despite an increase in runoff (and transport capacity), so the final equilibrium rate appears detachment-limited.

As predicted by Moss (1988) and Kinnell (1990), interrill erosion rate is directly proportional to runoff velocity. The less than linear relationship between soil loss and slope gradient observed for interrill erosion conditions (Lattanzi et al., 1974; McCool et al., 1987) appears to be a direct consequence of the influence of slope gradient on runoff velocity. Watson and Laflen (1986) found that the slope exponent for predicting soil loss was soil-sensitive. The relationship between runoff velocity and slope gradient is probably sensitive to surface roughness, and this may account for some of the soil sensitivity factor. Soil aggregate stability and aggregate breakdown product size distribution (Fox and Le Bissonnais, 1998) may also influence the slope of the relationship between soil loss and slope gradient by determining the settling velocity distribution of particles available for transport. In the field, slope gradient and aspect can affect rainfall impact gradient and discharge rate, and this would influence both detachment processes and runoff velocity (Torri, 1996).

The theory accounting for the linear relationship between soil loss and runoff velocity for turbulent rain-impacted flow erosion is expressed in terms of the influence of runoff velocity on transport capacity (Moss, 1988; Kinnell, 1990). However, the taper at steeper slope gradients predicted here for a constant runoff rate and observed by others (Meyer and Harmon, 1989) occurs within a regime which is probably detachment and not transport-limited. As noted above, sediment concentration decreased for all slope gradients after an initial surge despite an increase in runoff rate. Although the effect of runoff depth on detachment rate has been investigated (Palmer, 1964), the effect of runoff velocity on rain-impacted flow erosion detachment rate at the raindrop impact site has not been considered experimentally. It is likely that detachment at the impact site is enhanced by faster runoff flow velocities, and this area is in need of investigation. The 
theory of rain-impacted flow erosion could then be expressed in terms of both transport capacity and detachment processes, and not transport alone.

The results of the experiment have implications for interrill erosion studies in general. Since runoff velocity increased significantly over the $1 \mathrm{~m}$ distance investigated here, and since interrill runoff velocity is important for transport capacity and perhaps soil detachment, the interrill erosion rate will be strongly influenced by the size of the experimental soil tray or field plot and is therefore not independent of research scale. Bradford and Huang (1993) suggest that a $0.32 \mathrm{~m}^{2}$ soil tray may be representative of interrill conditions, but this is probably an underestimate except for crop interrow slopes which are very short. Soil tray size may indeed account for why Truman and Bradford (1995) observed greater splash erosion than rain-impacted flow erosion in their experiment. On longer slopes, interrill runoff will attain a greater runoff velocity, thereby increasing interrill erosion rate. In addition, the Manning equation does not appear suitable for interrill runoff as noted above, and experimental data are required to test the validity of the regression coefficients for interrill conditions.

\section{Conclusions}

The linear or less than linear relationship between interrill erosion rate and slope gradient noted by others was also observed in this study. For a constant runoff rate, soil loss increased roughly with the square root of slope gradient. Soil loss was probably detachment-limited for the entire range of slope gradients observed since the interrill erosion rate decreased after an initial surge despite an increase in transport capacity. Rain-impacted flow erosion accounted for more than $80 \%$ of the total erosion at all slope gradients.

A major influence of slope gradient on interrill erosion appears to be exerted through its impact on runoff velocity; among hydraulic parameters, soil loss was best correlated with flow velocity. Runoff velocity increases the transport capacity of runoff in rain-impacted flow erosion conditions. In addition, there may be an interaction between rain-impacted flow erosion detachment and runoff velocity, but this could not be proven in this experiment. The results indicate that runoff velocity must be measured routinely in interrill erosion experiments, as it is normally done in rill erosion studies. Two further areas of investigation with respect to runoff velocity and interrill erosion are: (1) the effect of surface roughness which influences both runoff velocity and detachment (Torri and Poesen, 1992), and (2) the effect of soil type and particularly soil aggregate stability which affects the particle size distribution of sediments available for transport (Fox and Le Bissonnais, 1998).

\section{Acknowledgements}

The research was supported by an operating grant to R.B. Bryan from the Natural Sciences and Engineering Research Council, Canada, which is gratefully acknowledged. The authors also gratefully acknowledge the helpful comments of Dr. D. Torri. 


\section{References}

Band, L., 1985. Field parameterization of an empirical sheetwash transport equation. Catena 12, 281-290.

Bradford, J.M., Huang, C., 1993. Comparison of interill soil loss for laboratory and field procedures. Soil Technology 6, 145-156.

Carson, M.A., Kirkby, M.J., 1972. Hillslope Form and Process. Cambridge Univ. Press, UK.

Fox, D.M., Le Bissonnais, Y., 1998. A process-based analysis of the influence of aggregate stability on surface crusting, infiltration, and interrill erosion. Soil Sci. Soc. Am. J., in press.

Fox, D.M., Bryan, R.B., Price, A.G., 1997. The influence of slope gradient on infiltration rate for interrill conditions. Geoderma 80, 181-194.

Gerits, J., De Lima, J., Van Den Broek, T., 1990. Overland flow and erosion. In: Anderson, M., Burt, T. (Eds.), Process Studies in Hillslope Hydrology. Wiley, Great Britain, pp. 173-214.

Govers, G., 1990, Empirical relationships for the transport capacity of overland flow. Erosion, transport, and deposition processes, Proceedings of the Jerusalem Workshop, March-April, 1987, IAHS Publication no. 189, pp. 45-63.

Govers, G., 1992. Relationship between discharge, velocity and flow area for rills eroding loose, non-layered materials. Earth Surface Processes and Landforms 17, 515-528.

Govers, G., Rauws, G., 1986. Transporting capacity of overland flow on plane and irregular beds. Earth Surface Processes and Landforms 11, 515-524.

Guy, B.T., Dickinson, W.T., Rudra, R.P., 1987. The roles of rainfall and runoff in the sediment transport capacity of interrill flow. Trans. Am. Soc. Agric. Eng. 30, 1378-1386.

Huang, C., Bradford, J., 1993. Analyses of slope and runoff factors based on the WEPP erosion model. Soil Sci. Soc. Am. J. 57, 1176-1183.

Kinnell, P., 1990, Modelling erosion by rain-impacted flow. In: Bryan, R.B. (Ed.), Soil Erosion, Experiments and Models. Catena Supplement 17, pp. 55-66.

Kinnell, P., Cummings, D., 1993. Soil/slope gradient interactions in erosion by rain-impacted flow. Trans. Am. Soc. Agric. Eng. 36, 381-387.

Kodama, H., Ross, G., Wang, C., MacDonald, K., 1993. Clay Mineralogical Database of Canadian Soils, Technical Bulletin 1993-1E, CLBRR contribution 92-82, Research Branch, Agriculture Canada.

Lattanzi, A., Meyer, L., Baumgardner, M., 1974. Influences of mulch rate and slope steepness on interill erosion. Soil Sci. Soc. Am. Proc. 38, 946-950.

Luk, S., Merz, W., 1992. Use of the salt tracing technique to determine the velocity of overland flow. Soil Technology 5, 289-301.

Mathier, L., Roy, A., 1996. A study on the effect of spatial scale on the parameters of a sediment transport equation for sheetwash. Catena 26, 161-169.

Mathier, L., Roy, A., Pare, J., 1989. The effect of slope gradient and length on the parameters of a sediment transport equation for sheetwash. Catena 16, 545-558.

McCool, D., Brown, L., Foster, G., Mutchler, C., Meyer, L., 1987. Revised slope steepness factor for the Universal Soil Loss Equation. Trans. Am. Soc. Agric. Eng. 30, 1387-1396.

McIsaac, G., Mitchell, J., Hirschi, M., 1987. Slope steepness effects on soil loss from disturbed lands. Trans. Am. Soc. Agric. Eng. 30, 1005-1013.

Meyer, L., Harmon, W., 1989. How row-sideslope length and steepness affect sideslope erosion. Trans. Am. Soc. Agric. Eng. 32, 639-644.

Moss, A.J., 1988. The effects of flow-velocity variations on rain-driven transportation and the role of rain impact in the movement of solids. Aust. J. Soil Res. 26, 443-450.

Moss, A.J., Walker, P.H., Hutka, J., 1978. Raindrop-stimulated transportation in shallow water flows: an experimental study. Sediment. Geol. 22, 165-184.

Palmer, R.S., 1964. The influence of a thin water layer on water-drop impact forces. International Association of Science and Hydrology. Publication 65, General Assembly, Berkeley.

Poesen, J., 1984. The influence of slope gradient on infiltration rate and Hortonian overland flow volume. Z. Geomorphol. N.F. Suppl.-Bd. 49, 117-131.

Poesen, J., Ingelmo-Sanchez, F., Mucher, H., 1990. The hydrological response of soil surfaces to rainfall as affected by cover and position of rock fragments in the top layer. Earth Surface Processes and Landforms $15,653-671$. 
Renard, K.G., Laflen, J.M., Foster, G.R., McCool, D.K., 1994. The revised universal soil loss equation. Soil Erosion Research Methods, St. Lucie Press, USA, pp. 105-126.

Rose, C.W., Williams, J.R., Sander, G.C., Barry, D.A., 1983. A mathematical model of soil erosion and deposition processes: I. Theory for a plane land element. Soil Sci. Soc. Am. J. 47, 991-995.

Shainberg, I., Warrington, D., Laflen, J.M., 1992. Soil dispersibility, rain properties, and slope interaction in rill formation and erosion. Soil Sci. Soc. Am. J. 56, 278-283.

Singer, M.J., Blackard, J., 1982. Slope gradient - interrill soil loss relationships for slopes up to 50\%. Soil Sci. Soc. Am. J. 46, 1270-1273.

Torri, D., 1996. Slope, aspect and surface storage. In: Agassi, M. (Ed.), Soil Erosion, Conservation, and Rehabilitation. Marcel Dekker, New York, pp. 77-106.

Torri, D., Poesen, J., 1992. The effect of soil surface slope on raindrop detachment. Catena 19, 561-578.

Truman, C.C., Bradford, J.M., 1995. Laboratory determination of interrill soil erodibility. Soil Sci. Soc. Am. J. $59,519-526$.

Walker, P.H., Kinnell, P.I.A., Green, P., 1978. Transport of noncohesive sandy mixture in rainfall and runoff experiments. Soil Sci. Soc. Am. J. 42, 793-801.

Watson, D., Laflen, J., 1986. Soil strength, slope, and rainfall intensity effects on interrill erosion. Trans. Am. Soc. Agric. Eng. 29, 98-102. 